\title{
PARA LER NORBERT ELIAS ${ }^{1}$
}

\author{
TO READ NORBERT ELIAS
}

Marcelo FONTENELLE E SILVA ${ }^{2}$

RESUMO: O presente artigo pretende apresentar as bases do pensamento e da sociologia de Norbert Elias (1897-1990), trazendo como auxílio para a compreensão de seu esquema teórico informações biográficas e uma sucinta discussão sobre algumas de suas obras. Os eixos da discussão estão nas considerações feitas pelo autor em relação às características da sociologia e sua especificidade enquanto ciência, baseando-se principalmente na distinção analítica entre envolvimento e alienação; e, também, na apresentação de seus principais conceitos e de como ele os operacionaliza em pesquisas empíricas. Pretendeu-se demonstrar, assim, como vida e obra de Elias estão interligadas e o potencial analítico do referencial por ele desenvolvido.

PALAVRAS-CHAVE: Norbert Elias. Introdução a Norbert Elias. Introdução à sociologia.

ABSTRACT: This article intends to introduce the foundations of Norbert Elias (1897-1990) sociology, taking as support for the understanding of his theoretical framework some biografic information and a discussion about some os his works. The axes of argumentation are based on considerations made by the autor about characteristics of sociology and their specificities, relying primarily on the analitical differences between involvment and detachment; the presentation of their main concepts and how he demonstrates it in researches. So, it was intended to demonstrate how life and work of Elias are interconnected and the analytical potential of his teory.

KEYWORDS: Norbert Elias. Introduction to Norbert Elias. Introduction to sociology.

\section{Introdução}

Na ambiguidade do título - "Para ler Norbert Elias" - se encontra o objetivo do presente artigo: pretende-se, de um lado, apresentar as informações e conceitos necessários para um leitor que pretende conhecer a obra de Norbert Elias; e, por outro, convencer o leitor da importância de visitar e revisitar sua obra, dando continuidade, por meio de pesquisas empíricas, reflexões teóricas e a total recusa a qualquer tipo de adesão dogmática ou

\footnotetext{
${ }^{1}$ Artigo produzido como parte da disciplina Teoria Sociológica, ministrada pelo professor Dr. Juarez Lopes, no primeiro semestre de 2015.

${ }^{2}$ Universidade Federal do Maranhão (UFMA), São Luiz - MA - Brasil. Mestrando no Programa de PósGraduação em Ciências Sociais. marcelofontenelle@ hotmail.com.
} 
ideológica (ou seja, tal qual ele fez com os autores que o precederam e seus contemporâneos), às questões levantadas e trabalhadas por ele.

Pode-se dizer, em termos mais pessoais e subjetivos, que uma das motivações deste artigo está na convicção, compartilhada com Elias, de que a sociologia tem um grande potencial de diminuir o sofrimento humano - ou, para usar termos que lhe eram caros, para cooperar com o aumento do autocontrole, com o desenvolvimento do processo civilizatório.

Vale frisar, também, que o objetivo aqui não é uma mera exposição hagiográfica, mas uma análise que leva em conta a tentativa/necessidade de distanciamento para uma análise mais sóbria e reflexiva - portanto, mais útil para o desenvolvimento das ciências sociais.

A exposição está dividida em três partes interligadas. A primeira objetiva, partindo principalmente da obra Norbert Elias por ele mesmo (ELIAS, 2001), apresentar informações sobre a vida do autor, algumas influências intelectuais e aspectos da recepção de sua obra; a segunda objetiva apresentar as peculiaridades das ciências sociais, conforme acepção de Norbert Elias; e a terceira, apresentar uma discussão envolvendo seus principais conceitos e obras em que ele os desenvolveu e operacionalizou.

\section{Notas sobre aspectos biográficos, influências intelectuais e recepção da obra}

Norbert Elias nasceu em Breslau, então cidade da Alemanha. Viveu nesta cidade até 1915, quando foi prestar o serviço militar - que durou até o fim da Primeira Guerra Mundial. Era filho único, de família judia e burguesa, relativamente abastada: seu pai tinha uma empresa do ramo têxtil, sua mãe não possuía trabalho remunerado, se dedicando às "atividades da casa".

Identificavam-se, conforme afirmação do próprio (ELIAS, 2001), tanto como judeus quanto como alemães. Ainda conforme seu relato, apesar de reconheceram a discriminação que sofriam, não possuíam noção de sua amplitude. Compreende-se, assim, o fato dos pais de Elias terem voltado para a Alemanha após visitá-lo na Inglaterra, a despeito de o nazismo já ter iniciado suas atrocidades - após algum tempo, ambos foram assassinados. Elias havia se mudado para a Grã-Bretanha em 1935.

Antes disso, porém, Elias relata entrar na guerra sem nutrir nenhuma convicção que tenha qualquer coisa que se possa relacionar com "nacionalismo" ou "patriotismo" (ELIAS, 2001). Saiu da guerra sem ter sido tão afetado quanto vários outros - como ele mesmo menciona, muitos voltaram sem nem mesmo conseguir falar -, que não quer dizer que tal experiência não tenha sido marcante na constituição das suas disposições e interesses. 
Elias havia se apresentado como voluntário, por orientação de sua família, que acreditava ser aquele trabalho menos perigoso, para trabalhar em linhas de transmissão telefônicas. Assim que chegou da guerra, iniciou os seus estudos em medicina e em filosofia cursou ambos paralelamente, até decidir por largar a medicina e prosseguir com a filosofia, objetivando a carreira acadêmica.

Quanto a seus estudos de medicina, Elias afirma que, paralelamente às experiências com a guerra, tiveram uma grande importância no abandona da filosofia e busca de algo mais real e concreto - a sociologia. Além do mais - e sua incessante interdisciplinaridade e vasto conhecimento da psicanálise atestam isso -, ele acreditava que “[...] um estudante de sociologia devia ter algumas noções essenciais da estrutura do sistema nervoso humano para ser capaz de se aproximar da concepção de homem indispensável à compreensão de contextos sociais." (ELIAS, 2001, p. 99).

Um dos muitos percalços durante sua trajetória foi à dificuldade financeira pela qual passou logo que acabaram os estudos de filosofia. Apesar de formado, não pôde exercer o ofício que escolheu e viu-se obrigado a arranjar emprego em uma fábrica. Trabalhou durante dois anos como "homem de confiança" do dono de uma fábrica - experiência que ele diz ter sido muito válida para a sua formação de sociólogo e determinante na sua compreensão do capitalismo e da economia. Assim que os pais se restabeleceram financeiramente, porém, Elias largou o seu trabalho na fábrica e voltou a se dedicar aos estudos universitários.

Elias deixou o trabalho na fábrica em Breslau e seguiu para Heidelberg. Conforme seu próprio depoimento:

Naquela época, Heidelberg era uma espécie de Meca da sociologia. O grande Max Weber morrera, é verdade, mas sua viúva ainda vivia, e seu irmão Alfred igualmente, ele também professor de sociologia [...]. O florescimento da sociologia começou, portanto, desde a época imperial, mas acentuou-se de fato apenas depois de 1918. (ELIAS, 2001, p. 44).

Lá, manteve contato com inúmeros sociólogos, incluindo Karl Mannheim, de quem logo se tornou assistente e exerceu grande influência em seu pensamento (não só com aproximações, mas talvez, principalmente, distanciamentos). Adentra aos círculos da viúva de Max Weber, Marianne Weber, e tem aulas com seu irmão, Alfred Weber. Cidade basicamente universitária, Heidelberg era um lugar de grande efervescência intelectual.

Outro ponto de seu livro memorialístico que chama atenção é a crença de que sua obra “triunfaria”. Diz ele: “[...] ou eu triunfava, ou desaparecia. Não tinha certeza absoluta, 
naturalmente, mas não duvidava nem um pouco de que minha obra um dia seria reconhecida como contribuição de qualidade ao saber da humanidade." (ELIAS, 2001, p. 22).

Algo que corrobora com sua fala e aponta para o fato de isto não ser uma mera reconstrução a posteriori está na "coerência" de suas obras durante o longo tempo de atuação intelectual. Vale lembrar: Elias viveu quase todo o século XX, tendo produzido trabalhos até uma idade bastante avançada. Desde a produção de $O$ Processo Civilizador (feito na Inglaterra, na segunda metade da década de 30), até a sua morte, não há incongruências ou mudanças teóricas drásticas, mas o desenvolvimento de um mesmo programa de pesquisa.

Pelo que parece, portanto, toda a longa demora no reconhecimento e valorização da obra de Elias não serviu para abalar a crença que ele tinha no valor de sua obra. As restrições materiais que passou por certos momentos e a necessidade de sair perambulando atrás de emprego em uma universidade (só conseguiu se tornar professor com 59 anos, em Leicester), bem como fugindo da violência nazista, não o impediram de dar cabo ao seu projeto inicial e, felizmente, ele ainda conseguiu usufruir de certas retribuições (materiais e simbólicas) em vida- autores como Walter Benjamin tiveram um “destino” bem mais trágico. Hoje, Elias é um autor relativamente conhecido. No Brasil, parte muito significativa de sua obra já foi traduzida.

Segundo Nathalie Heinich (2001), um fator que provavelmente contribuiu para a demora no reconhecimento da obra de Elias (que, segundo ela, ainda não obteve o reconhecimento e a influência que deveria) foi o fato de ele escrever "em espiral" - ou seja, com a aparência de se repetir várias vezes, por mais que a cada vez ele acrescente algo diferente. Outra explicação, que se soma à anterior, vem de A. Garrigou e B. Lacroix (2010), que sugerem que um dos fatores que explicam a demora na publicação e reconhecimento da obra eliasiana foi o fato de ele sempre se situar "na contracorrente", pois recusou as ideias dominantes (cheias de ideologias, como ele mesmo menciona nas já citadas memórias) e recusou abandonar seus compromissos intelectuais em prol de "causas" consagradas no meio intelectual de então (como Karl Popper e a visão liberal e de Mannheim e a socialdemocracia). Como dizem os autores:

Semelhante recusa - quase jansenista de exploração das circunstâncias para a sua vantagem - nunca reuniu as multidões: no contexto do pós-guerra depois da guerra fria, a recusa apoiada de toda facilidade militante - que ainda não se chamava engajamento -, mais a defesa intratável de posições materialistas e históricas, nada tinha de muito atraente. Tudo isso colocava Norbert Elias no lado errado, ou, melhor, afastava-o de todos os lados. (GARRIGOU; LACROIX, 2010, p.XXII) 
Os dois autores mencionam ainda que não haja pesquisas suficientes para proporcionar a compreensão, de forma satisfatória, da descoberta e ascendente difusão da obra de Norbert Elias - resta, aí, um fértil espaço de pesquisa em aberto.

\section{As dificuldades e as tarefas das ciências sociais}

A apreensão da sociologia sobre a relação entre indivíduo e sociedade foi alvo da preocupação de Elias em muitos de seus escritos. Em Introdução à Sociologia, Elias (1999) traz que é necessário, para dar conta do seu papel de sociólogo, que o próprio pesquisador compreenda que ele próprio é parte da sociedade que estuda.

Esta aparência de separação não se dá apenas no exercício sociológico, mas se apresenta dentre os indivíduos e a sociedade como um todo. As configurações sociais com as quais o indivíduo tem contato - a família, o Estado, etc. - aparecem como algo exterior aos indivíduos ou como objetos estáticos - ou seja, aparecem de forma reificada. Como diz Elias:

Conceitos como 'família' ou 'escola' referem-se essencialmente a grupos de seres humanos interdependentes, a configurações específicas que as pessoas formam umas com as outras. Mas a nossa maneira tradicional de formar esses conceitos faz com que esses grupos formados por seres humanos interdependentes apareçam como bocados de matéria-objetos tais como as rochas, árvores ou casas. (ELIAS, 1999, p. 13-14).

Em se tratando especificamente das ciências sociais, algo que reforça esta tendência a pensar de modo reificado é a transposição automática - ou quase - de modos de pensar e falar que foram desenvolvidos com base e para as ciências da natureza. Percebe-se que as formas de pensamento que estão à disposição são baseadas ou no modelo mágico-mítico, ou nos modelos retirados das ciências naturais - o que gera uma série de incompreensões e equívocos.

Pode-se afirmar, portanto, que não encontramos prontos os mecanismos, palavras e conceitos adequados para descrever e pensar as relações e processos humanos - a construção gradativa destes mecanismos é um dos papéis primordiais da sociologia. Não à toa, grandes autores das ciências sociais e humanas desenvolveram o que pode ser chamado como uma "gramática" própria.

Pierre Bourdieu, por exemplo, cunhou conceitos como habitus, campo e illusio. Por mais que ele tenha se baseado explicitamente em outros autores e que inclusive outros já fizessem referência a alguns desses termos (Elias é muito claro quando menciona que a construção destes conceitos não é tarefa de um homem só, mas de várias gerações), a 
apropriação e articulação entre tais conceitos é própria de um esquema teórico-analítico específico que, por mais que seja possível e desejável fazer críticas, cooperou bastante para adensar a compreensão das disputas e dos mecanismos de estratificação e dominação da sociedade contemporânea.

Tanto para as ciências sociais quanto para as ciências naturais, diz Elias, "[...] o modo científico dá às pessoas a possibilidade de distinguir mais claramente, à medida que se vai avançando, as ideias fantasiosas das realistas." (ELIAS, 1999, p. 23). O desenvolvimento da cientifização do pensamento, portanto, ocorre paralelamente ${ }^{3}$ à diminuição das ideias fantasiosas e ao aumento do domínio da realidade que nos cerca.

Não é raro, por exemplo, vermos pessoas atribuindo a "culpa" do desemprego à invenção de poderosas máquinas que substituem a mão-de-obra humana. Ou a "culpa" da guerra à invenção das armas, ou às vontades dos deuses. As máquinas, porém, não tem vontade própria - assim como os deuses. E acabamos por atribuir a elas (pelo processo que Elias chamou de 'deslocação') o que na verdade decorre de processos protagonizados por indivíduos interdependentes em conflito (ELIAS, 1999).

Outro livro de Norbert Elias (1998), intitulado Envolvimento e Alienação, nos ajuda a compreender algumas das dificuldades de se construir um conhecimento de fato realista e as distinções entre as ciências humanas e não-humanas.

Conforme esta obra, para obter um conhecimento mais realista do mundo, é necessária sustentar uma postura que seja mais alienada ${ }^{4}$ e menos envolvida. Segundo Heinich, o que Elias faz é acentuação da defesa da neutralidade axiológica weberiana. Nas palavras dela:

Elias é então um ardente defensor da 'neutralidade axiológica' já preconizada por Max Weber, esperando do sociólogo que ele se libere da ideia que a sociedade estudada deva corresponder a seus ideais [...]. A condição deste afastamento é a capacidade de 'distanciamento' do cientista com relação a seus próprios afetos: distanciamento que é, ao mesmo tempo, o produto de uma evolução histórica no interior do 'processo de civilização', e a condição de sua própria efetivação, que favorece a própria consciência desta condição e de sua necessidade. (HEINICH, 2001, p. 149-150).

\footnotetext{
${ }^{3}$ A não implicação de uma relação de causa e efeito é proposital e decorre de uma fundamentação teórica, como veremos mais à frente.

4 Em outros trabalhos publicados, optou-se pela tradução do termo por 'autodistanciamento', ao invés de alienação. Optei por utilizar aqui o termo conforme a tradução que tive acesso, da editora Bertrand Brasil, mas creio ser necessário deixar claro que, com alienação, não se refere a um termo negativo, seja conforme o senso comum, onde alienação se refere ao desconhecimento das questões políticas consideradas como importantes, ou conforme o termo marxiano, onde alienação se refere a um processo que se dá no âmbito do trabalho, em que há um estranhamento do homem consigo mesmo e com o produto de sua atividade.
} 
O pensamento mitológico e o reificado são exemplos de formas de pensar em que o envolvimento é preponderante. Não se deve, porém, utilizar os conceitos de envolvimento e alienação para classificar obras, como se houvesse ali uma linha separando uma coisa envolvida de uma alienada. Deve-se, diferentemente, utilizar dos conceitos para analisar as ações das pessoas em ambas as direções: "o contínuum que reside entre esses pólos marginais é o que se configura como questão principal” (ELIAS, 1998, p. 108).

Um dos aspectos característicos do modo mais alienado de pensar a realidade é a perspectiva de longo prazo. Não é que o estudo do tempo presente seja uma questão de envolvimento. O que é, de fato, um erro, é não situar o estudo do presente, ou qualquer outro, em um processo contínuo, que se estende pelo passado e estenderá para o futuro.

Conforme nos ensina Elias (ELIAS, 1998), os tempos de maior perigo - e, portanto, menor autocontrole - são menos propícios para a construção de formas mais alienadas de pensamento. Isto aconteceu no que tange às ciências naturais, quando a natureza apresentava grandes perigos e os homens eram obrigados a pensar e agir de acordo com as necessidades imediatas; e acontece hoje, no que tange às ciências humanas, em momentos em que a ameaça de guerra entre Estados com um gigantesco potencial destrutivo paira sob a cabeça de muitos ${ }^{5}$. Há, portanto, “[...] interdependência circular entre os avanços do conhecimento mais alienado e mais congruente com a realidade, e os decréscimos no nível social de perigo e medo." (ELIAS, 1998, p. 40-41).

Sem objetivar se estender muito - por uma questão de espaço - quanto à relação entre o estágio do processo civilizador e o desenvolvimento da alienação nas ciências sociais e nas ciências naturais, nos limitaremos aqui à afirmação, longamente desenvolvida por Elias nos seus dois livros citados neste tópico (ELIAS, 1998, 1999), que vivemos hoje uma forte discrepância entre os níveis de alienação destes dois campos de conhecimento.

Uma das características fundamentais da nossa época: esta reside na discrepância entre, por um lado, a nossa capacidade relativamente grande de ultrapassarmos - de um modo adequado e realista - problemas causados por acontecimentos naturais e extra-humanos, e, por outro, a nossa limitada capacidade de resolver com a mesma segurança os problemas da coexistência humana. (ELIAS, 1999, p. 26).

Segundo Elias, porém, não há nada que nos leve a crer que não seja possível chegar a um mesmo nível de fidelidade à realidade quanto à compreensão dos fenômenos humanos.

${ }^{5}$ A utilização da guerra como um exemplo pode não parecer tão clara, hoje, quanto no período em que Elias escreveu - marcado por duas Guerras Mundiais e a chamada Guerra Fria. Mas a comparação contínua válida, na medida em que o nível de alienação em relação às ciências humanas não parece ter se alterado drasticamente da segunda metade do "pequeno século XX" até os dias de hoje. 
Conforme nos relembra Nathalie Heinich, "Elias acredita[va] firmemente na possibilidade de uma ciência do homem, acessível à verificação pela confrontação com os dados objetivos em objetos, em palavras ou em números - e ele contribui para a sua construção." (HEINICH, 2001, p. 145).

\section{A "gramática" eliasiana}

É muito provável que a obra mais importante do Norbert Elias seja os dois volumes reunidos aqui no Brasil sob o título de $O$ Processo Civilizador. Apesar de escrito quando ele era ainda jovem - a primeira edição publicada data de 1939, na Suíça -, nesta obra Elias põe em marcha todo o seu esquema analítico, analisando fartos materiais empíricos, e expõe as bases teóricas e epistemológicas de sua sociologia, expondo assim um grande programa de pesquisa.

Nest livro, Elias demonstra que o processo civilizador é uma mudança em uma direção específica, mas não é produto da intenção deliberada de um indivíduo ou grupo, mas de longos processos conflituosos entre indivíduos interdependentes. Não só o processo civilizador como um todo, mas os processos humanos são também mudanças de caráter não planejado. Há, de fato, certo nível de possibilidade de intervenção planejada, mas ele varia de acordo com o aumento do conhecimento da dinâmica não-planejada da vida social - ou seja, a sociologia aumenta a possibilidade de autocontrole.

Assim, o processo civilizador segue na direção da estabilização e generalização do autocontrole. Como mencionou Elias:

O controle efetuado através de terceiras pessoas é convertido, de vários aspectos, em autocontrole, (que) as atividades humanas mais animalescas são progressivamente excluídas do palco da vida comunal e investidas de sentimento de vergonha, (que) a regulação de toda a vida instintiva e afetiva por um autocontrole se torna cada vez mais estável, uniforme e generalizada. (ELIAS, 1993, p. 194).

Conforme demonstrado teórica e empiricamente por ele, este aumento do autocontrole se dá a partir de alguns fatores interdependentes: a sintonização de um número cada vez maior de indivíduos, a organização da vida de forma mais rigorosa e precisa, uma maior diferenciação das funções sociais e uma maior regulação (estabilização e uniformização) da conduta humana.

O autocontrole se dá tanto no âmbito consciente quanto no "automático". Com o desenrolar do processo civilizador, a complexificação e estabilização do controle da conduta 
passa a ser instilada no indivíduo desde os seus primeiros anos de vida, levando a uma espécie de autocontrole automático, cego - daí a importância, reafirmada em outra obra sua (ELIAS, 1995), da análise dos primeiros anos da vida do indivíduo para a compreensão do processo civilizador individual - ou psicogênese/ontogênese.

Outro aspecto importante na estabilização e desenvolvimento do autocontrole mental está na monopolização da força física por um príncipe/instituição e na estabilização dos órgãos centrais da sociedade - o que nos remete diretamente à dinâmica da constituição do Estado. Com estes três processos interdependentes, o indivíduo deixa de se sentir ameaçado e deixa de dar vazão às suas pulsões, ao menos com a mesma intensidade de outrora.

As sociedades de corte dos séculos XVII e XVIII são um exemplo bastante profícuo para a compreensão dos processos civilizadores e, mais especificamente, do processo civilizador que passou a civilização ocidental. O processo de transformação da nobreza belicosa em nobreza domada (ou, o que dá no mesmo, de guerreiros em cortesãos), teve o seu auge nos dois séculos mencionados, mas se iniciou por volta do século XI.

Inicialmente, havia um grande número de castelos e um baixo grau de integração entre estas configurações, havendo uma série de conflitos que permaneciam mais ou menos isolados. Processual e lentamente, dá-se a centralização de terras e castelos por meio de batalhas e o aumento do poderio militar. Assim, a teia de interdependência em que se situava o guerreiro se torna mais extensa, o que o obriga a tomar um maior número de reservas e limitações em sua conduta.

Um dos fatores determinantes neste processo foi a ascensão da burguesia, que passou a conviver constantemente com a nobreza nos meios corteses. Tal convivência, além de aumentar bastante o número de conflitos, levou também ao entrelaçamento entre burguesia e nobreza, aumentando assim a rede de interdependência às quais ambas estavam ligadas. Sentindo-se ameaçados em relação a seus prestígios por conta da ascensão da burguesia, aumentou também, dentre os nobres, a exigência mútua de autodomínio, a necessidade de afirmação das distinções. Assim, afirma Elias (1993, p.225):

A interdependência mais estreita de todos os lados, a pressão mais forte
vinda de todas as direções, exige e instila um autocontrole mais uniforme,
um superego mais estável e novas formas de conduta entre as pessoas: os
guerreiros tornam-se cortesãos.

Em outro texto, publicado bem depois de O Processo Civilizador e em meio à Guerra Fria e, portanto, na possibilidade de uma guerra atômica, Elias afirma que, se analisarmos em longo prazo e de forma geral o desenvolvimento da humanidade, o processo de civilização se 
fez dominante, por mais que haja sempre embates, idas e vindas com processos descivilizatórios - não há nada, porém, que garanta a perpetuação deste predomínio (ELIAS, 2006).

Os processos civilizadores, apesar de terem algumas características universais (como a tendência a transformação do controle social em autocontrole), têm também peculiaridades próprias de cada configuração, e Elias não deixa de perceber estas especificidades contrariando, assim, alguns de seus críticos. Conforme podemos ver no trecho seguinte, a partir da operacionalização do conceito de habitus social:

[...] é variado o desenvolvimento dos processos especiais de civilização, assim como de cada figuração ${ }^{6}$ dos modelos de civilização. Estes últimos encontram uma de suas expressões mais prementes no habitus social comuns dos indivíduos que formam entre si uma determinada unidade de subsistência, por exemplo, uma tribo ou Estado. Eles são herdeiros não só de uma linguagem específica, mas também de um modelo específico de civilização e, portanto, de formas específicas de auto-regulação, que eles absorvem mediante o aprendizado de uma linguagem comum e nas quais, então, se encontram: no caráter comum do habitus social, da sensibilidade e do comportamento dos membros de uma tribo ou de um Estado nacional. (ELIAS, 2006, p. 23).

Interligada a toda esta discussão está à distinção operada por Elias quanto à relação entre estabelecidos e outsiders. Este par conceitual tem presença marcante tanto nas análises de Elias quanto aos judeus na Alemanha ${ }^{7}$, conforme se pode ver em suas já citadas memórias, quanto no famoso livro de Elias e Scotson intitulado Os estabelecidos e os outsiders (ELIAS, 2000), onde ele analisa a coexistência de dois grupos em uma comunidade inglesa da década de 50, quanto na análise da vida do músico burguês Mozart, dentre outros - enfim, ocupa uma posição central no esquema teórico-metodológico de Norbert Elias.

Como nos diz Elias, “[...] a vida de Mozart ilustra nitidamente a situação de grupos burgueses outsiders numa economia dominada pela aristocracia de corte [...]" (ELIAS, 1995, p. 16). Apesar da proximidade da Revolução Francesa (Mozart viveu na segunda metade do século XVIII), a vida de Mozart se deu toda sem que ele pudesse ver o establishment cortesão ser efetivamente ameaçado. Mozart, assim como o seu pai, era um músico burguês que não

${ }^{6}$ Os tradutores do presente texto, que é composto por três verbetes escritos por Elias para um dicionário de sociologia, optaram por utilizar figuração, ao invés de configuração, alegando que o próprio Elias, em seus escritos, oscilava entre ambos. O mesmo vale para a distinção entre "processo de civilização" e "processo civilizador". Para um debate mais aprofundado sobre isto, ver a "Apresentação", escrita por Federico Neiburg e Leopoldo Waizbort, da coletânea de textos intitulada Escritos \& Ensaios, e também organizada por eles (NEIBURG; WAIZZBORT, 2006).

${ }^{7}$ Sobre o processo (des)civilizador na região da Alemanha pode-se ver, além das citadas considerações tecidas em seu livro de memórias e do livro sobre a trajetória de Mozart, o livro Os Alemães: a luta pelo poder e a evolução do habitus nos séculos XIX e XX (ELIAS, 1997). 
possuía outra opção a não ser servir à nobreza de corte - eram eles que estabeleciam os padrões a serem seguidos pelos artistas e que majoritariamente consumiam criações artísticas. Diferentemente da literatura e da filosofia (em que já havia um público leitor burguês em ascensão, capaz de consumir e bancar a produção de livros), o meio musical era completamente dependente, tanto material quanto simbolicamente, dos círculos aristocráticos. Em termos hierárquicos, os músicos estavam lado a lado dos pasteleiros e criados, e eram tão indispensáveis quanto eles. Tal situação fazia com que as relações de poder entre os estabelecidos ${ }^{8}$ economicamente (os nobres corteses) e os outsiders burgueses vivendo na corte fosse bastante desfavorável a estes últimos.

Apesar de tal conflito, a relação de Mozart com a corte era ambivalente. Além de ter nos aristocratas o seu principal público (o único possível), ele não rompe com o modo de compor da aristocracia e, de certa forma, leva em conta os seus valores - a relação com a corte, portanto, não era puramente negativa.

Como se pode ver, para análise sociológica da vida de Mozart, Elias mobiliza de forma bastante recorrente a distinção entre estabelecidos-outsiders, mas também se utilizado conceito de habitus, configurações, dentre outros. Operacionaliza sua concepção não reificada de indivíduo e, consequentemente, de como se dá as relações de poder travadas entre eles. Ou seja, ele opera com o processo civilizador tanto no nível do individuo (ontogênese/psicogênese) quanto no nível societal (ELIAS, 1995).

Em seu já citado livro de "autobiográfico", Elias afirma que a delicada e singular experiência vivida por ele na Alemanha, sentindo-se pertencente ao grupo estigmatizado composto pelos judeus ao mesmo tempo em que era muito fortemente ligado à tradição cultural alemã (ele chega a afirmar que por vezes não se percebiam enquanto grupos distintos), "era efetivamente um problema de relações entre grupos estabelecidos e grupos outsiders" (ELIAS, 2001, p. 135).

Como um grupo outsider, os judeus eram excluídos de uma série de "benefícios", que serviam também de distinção entre os grupos, ou seja, para reafirmar a posição subjugada de uns em relação ao status superior de outros. Acontece, porém, que o nível de tolerância do grupo estabelecido e a tensão entre os grupos variam principalmente com a possibilidade de ascensão dos outsiders, como se pode ver não só em relação aos judeus e o nazismo, mas também em relação aos negros e a Ku Klux Klan nos Estados Unidos, etc.

${ }^{8}$ Sérgio Goes de Paula - tradutor do livro Mozart: sociologia de um gênio (ELIAS, 1995) no Brasil optou por não utilizar o termo "estabelecidos", mas stablishment. Manteremos o termo "estabelecidos", a fim de manter uma coerência ao longo do artigo. 
Outro fator potencializador da tensão entre os judeus e os grupos estabelecidos foi o pouco tempo decorrente desde que a sociedade alemã ascendera relativamente aos demais Estados nacionais europeus. Esta situação de instabilidade e fragilidade dos recém estabelecidos cooperou para a ocorrência de ações tão violentas e extremadas por parte dos recém estabelecidos. Soma-se a isto o fato de que os judeus, diferentemente de outros grupos outsiders, não se consideravam como um grupo inferior, e não se comportavam como um grupo inferior nos domínios que tinham um relativo acesso - notadamente, na cultura e economia, onde não raras vezes ocupavam posição de destaque (ELIAS, 2001).

Em seu estudo sobre Winston Parva (a comunidade inglesa estudada por Elias e Scotson em fins da década de 50, que resultou no livro intitulado Os Estabelecidos e os Outsiders) Elias percebe que a diferença entre os dois grupos que lá coabitavam não era econômica, mas sim decorrente de que os residentes de uma das zonas se instalaram duas ou três gerações anteriormente e, assim, criou-se uma relação de desigualdade entre os grupos, onde os mais velhos - os estabelecidos - possuíam um forte sentimento de pertencimento e viam os recém chegados como subjugados, inferiores, marginalizados.

Este estudo é, segundo Martuccelli, paradigmático para compreender não só como Elias articula o par conceitual estabelecidos-outsiders, mas também como se dá a sua concepção de indivíduo e como a noção de configuração tenta resolver certos problemas e ambiguidades teóricas do seu esquema teórico.

Segundo Martuccelli (2000, p. 48) “[...] para Elias, o principal problema do indivíduo na modernidade é menos o de visar a se dotar de sua própria lei de maneira autônoma, ou de realizar sua indiferença comunitária, que de organizar o autocontrole das tentações que expõe a modernidade." "Percebe-se, assim, o caráter central que ocupa o autocontrole nas análises eliasianas e, também, segundo a avaliação deste autor, o autocontrole como um critério tanto analítico quanto de avaliação moral. Se o autocontrole o é, a configuração estabelecidosoutsiders não poderia deixar de ser, pois o que distingue os estabelecidos dos outsiders, antes de tudo, seria a sua capacidade de autocontrole - outros fatores também influenciam como a coesão, a solidariedade, e o diferencial de integração. Martuccelli apresenta, assim, certas ambiguidades e paradoxos.

Segundo este autor, o autocontrole não é - como quer Elias - fruto das interdependências, mas do diferencial de recursos e coesões. Além do mais, o esquema

${ }^{9}$ Tradução livre feita a partir do original em francês. 
analítico de Elias operaria com a pressuposição de domínios bem delimitados - as configurações -, coisa que nem sempre acontece ${ }^{10}$.

Contra qualquer possibilidade de análise reificada ou substancialista, Elias nos ensina “[...] que o conceito de indivíduo se refere a pessoas interdependentes, e o conceito de sociedade a pessoas interdependentes no plural [...]" (ELIAS, 1999, p.136). Assim, para sanar a infértil polêmica que opõe indivíduo e sociedade, Elias traz o conceito de configuração. Com este conceito, ele designa um conjunto de indivíduos interdependentes que formam um padrão mutável. Assim, Elias opera com uma concepção de indivíduo e de poder que são interdependentes:

No seio das configurações mutáveis - que constituem o próprio centro do processo de configuração - há um equilíbrio flutuante e elástico e um equilíbrio de poder, que se movo para diante e para trás, inclinando-se primeiro para um lado e depois para outro. Este tipo de equilíbrio flutuante é uma característica estrutural do fluxo de cada configuração. (ELIAS, 1999, p. 143).

Elias prossegue mencionando que o conceito de configuração pode ser usado para designar tanto clientes frequentes em um bar quanto habitantes de uma nação, por exemplo. Ou seja, tanto para grupos relativamente pequenos de indivíduos interdependentes, quanto para os grandes. O que difere é o tamanho e a diferenciação das cadeias de interdependência que os ligam.

\section{Considerações finais}

Em consonância com o objetivo acima exposto, tentei demonstrar os fundamentos teóricos e epistemológicos da sociologia de Norbert Elias, apresentando algumas de suas obras e possibilidades de desdobramentos. Apesar da aparente simplicidade do objetivo, tal tarefa apresentou certas dificuldades, a começar pela escolha das obras a serem discutidas e os pontos a serem aprofundados. Deve-se ressaltar, assim, que a necessidade de seleção e recorte talvez transpareça uma simplificação da obra de Norbert Elias. Faz-se necessário, por isso, enfatizar o caráter necessária e sabidamente parcial do presente trabalho.

O tratamento dos aspectos biográficos, por exemplo, apesar de ser sem dúvida essencial para a compreensão de qualquer autor, focou-se em dar voz a Norbert Elias, a partir de seu livro de memórias, o que implica em reproduzir uma série de lacunas. Além disto,

10 Tais críticas, porém, são questionáveis. Uma discussão mais aprofundada sobre as mesmas necessitaria um debate mais extenso, que contasse não só com o recurso às demais obras de Elias, mas também de outros comentadores. Apesar de frutífera e interessante, tal empreitada foge ao objetivo do presente trabalho. 
deve-se atentar para o fato de que a exposição cronológica dos eventos pode nos incitar a recair nos erros da "ilusão biográfica", para utilizarmos palavras de Bourdieu (2006), como se o desenrolar da vida fosse algo que seguisse uma sequência racional e previamente planejada,algo que também iria diretamente contra os ensinamentos de Elias, baseados na recusa da teleologia (HEINICH, 2001).

Cabe reiterar, por fim, que a distinção entre os três tópicos aqui dispostos não deve ser tomado de forma rígida, mas apenas como uma maneira de divisão que facilite a leitura e sistematização. As experiências vividas por Norbert Elias estão diretamente ligadas às suas preocupações ao longo da vida, que também estão diretamente ligadas ao desenvolvimento de sua carreira intelectual, seja em relação às suas afinidades culturais, aos seus temas de pesquisa escolhidos ou ao referencial teórico por ele desenvolvido.

\section{REFERÊNCIAS}

BOURDIEU, P. A ilusão biográfica. In: AMADO, J.; FERREIRA, M. M. (Org.). Usos \& abusos da história oral. 8. ed. Rio de Janeiro: Fundação Getúlio Vargas, 2006. p.183-191.

ELIAS, N. Conceitos sociológicos fundamentais. In: ELIAS, N. Escritos e ensaios.

Organização e apresentação de Federico Neiburg e Leopoldo Waizbort. Rio de Janeiro. Jorge Zahar, 2006. p.21-35.

ELIAS, N. Norbert Elias por ele mesmo. Rio de Janeiro: Zahar, 2001.

ELIAS, N. Os estabelecidos e os outsiders: sociologia das relações de poder a partir de uma pequena comunidade. Rio de Janeiro: Zahar, 2000.

ELIAS, N. Introdução à sociologia. Lisboa: Edições 70, 1999.

ELIAS, N. Envolvimento e alienação. Rio de Janeiro: Bertrand Brasil, 1998.

ELIAS, N. Os alemães: a luta pelo poder e a evolução do habitus nos séculos XIX e XX. Rio de Janeiro: Zahar, 1997.

ELIAS, N. Mozart: sociologia de um gênio. Rio de Janeiro: Zahar, 1995.

ELIAS, N. O processo civilizador. Rio de janeiro: Zahar, 1993. (Formação do Estado e civilização; v. II).

GARRIGOU, A.; LACROIX, B. Introdução: Norbert Elias: o trabalho de uma obra. In: GARRIGOU, A.; LACROIX, B. (Org.). Norbert Elias: a política e a história. São Paulo: Perspectiva, 2010. p. 9-22.

HEINICH, N. A sociologia de Norbert Elias. Bauru: EDUSC, 2001. 
MARTUCCELLI, D. La notion d'individu chez Norbert Elias. Talmutes, Paris, n. 15, p. 45$65,2000$.

NEIBURG, F.; WAIZBORT, L. Apresentação. In: ELIAS, N. Escritos e ensaios.

Organização e apresentação de Federico Neiburg e Leopoldo Waizbort. Rio de Janeiro. Jorge Zahar, 2006. p. 7-21.

\section{Como citar este artigo}

FONTENELLE E SILVA, Marcelo. Para ler Norbert Elias. Rev. Sem Aspas, Araraquara, v.6, n.1, p. 26-40, jan./jun. 2017. e-ISSN 2358-4238.

Submetido em: 10/05/2017

Aprovado em: 30/06/2017 